J. Jacobeit $\cdot$ H. Wanner $\cdot$ J. Luterbacher $\cdot$ C. Beck

A. Philipp · K. Sturm

\title{
Atmospheric circulation variability in the North-Atlantic-European area since the mid-seventeenth century
}

\begin{abstract}
Based on monthly mean sea level pressure grids objectively reconstructed by Luterbacher et al. variations of dynamical modes of the atmospheric circulation for January and July are described by novel indices for running 31-year periods between 1659 and 1999. These indices reflect the continuous evolution of the atmospheric circulation not only with regard to frequency changes of major dynamical modes but also in terms of internal changes within each mode concerning both dynamic (vorticity, intensity) and climatic properties (Central European temperature and precipitation during occurrence of each mode, respectively). Results indicate the great importance of within-mode variations: the zonal circulation mode in January, varying in frequency with long-term cycles, primarily changed its dynamic and climatic properties (towards higher indices) during the transition from the Little Ice Age to modern conditions between 1800 and 1930. Within the Russian High mode of January a change in preference from easterly to westerly patterns above Central Europe occurred around 1850. For July, a striking frequency maximum of the westerly mode at the end of the eighteenth century coincided with a period of marked summer warmth in Central Europe due to negative/positive deviations in vorticity/temperature during occurrence of this mode. The long-term evolution in July indicates a general increase of anticyclonic conditions strengthening during the last 50 years towards a unique phenomenon within the last centuries. The strong increase in the winter-time westerly circulation during the last decades,
\end{abstract}

J. Jacobeit $(\bowtie) \cdot$ C. Beck · A. Philipp · K. Sturm Institute of Geography, University of Würzburg, Am Hubland, D-97074 Würzburg, Germany E-mail: jucundus.jacobeit@mail.uni-wuerzburg.de

H. Wanner · J. Luterbacher

Institute of Geography, University of Berne,

Hallerstr. 12, CH-3012 Bern, and

National Center of Competence in Research (NCCR) in Climate, Erlachstr. 9a, 3012 Bern, Switzerland however, does not appear extraordinary in view of the low-frequency variations of this mode.

\section{Introduction}

Most of the empirical investigations on atmospheric circulation variability are confined to periods not exceeding some 15 decades at best due to the restricted availability of appropriate observations. For longer time periods various proxy data have been used, for example from ice cores (Appenzeller et al. 1998), tree rings (Cook et al. 1998), both in combination (Cullen et al. 2000; Cook et al. 2002; Glueck and Stockton 2001) or from documentary sources (Garcia et al. 2000; Rodrigo et al. 2001), to reconstruct particular aspects of circulation dynamics. These studies, however, are constrained to refer to more simple indices describing circulation variability (e.g. indices for the North Atlantic Oscillation NAO) rather than allowing analyses of the variations in large-scale fields of pressure or other dynamic parameters. In addition, objections have recently been raised concerning the reliability of proxy based indices to represent circulation variability sufficiently (Schmutz et al. 2000; Cullen et al. 2000).

Referring to the North-Atlantic-European region, large-scale pressure fields for historical periods were first derived subjectively by Lamb and Johnson (1966) back to the 1750 s and, on a daily scale, by Kington (1988) for the 1780s. Later on, monthly SLP maps were reconstructed for the Late Maunder Minimum period (Wanner et al. 1994) and for anomalous months of the sixteenth century (Jacobeit et al. 1999). Monthly mean sea-level pressure (SLP) grids objectively reconstructed from observed historical time series by means of EOFregression techniques were first produced by Jones et al. (1987) going back to 1780 for the North-AtlanticEuropean area. During the 1990s observed historical time series became increasingly available in particular 
for many regions of Europe (e.g. Jones et al. 1997; Bärring et al. 1999). Thus, enhanced or further extended reconstructions of historical SLP grids have been performed by Jones et al. (1999) and Luterbacher et al. (2002a) with the latter one extending back to 1659 on a monthly scale and even back to 1500 on a seasonal scale.

These objectively reconstructed grids now allow a considerable extension of periods to be statistically analysed for circulation variability. Such extended periods are highly important for evaluating circulation types, amplitudes and sequences of natural variability which are only partly included within short intervals such as the NCEP/NCAR reanalysis-period of just half a century (Kalnay et al. 1996; Kistler et al. 2001). Furthermore, the extended periods reach back into times without significant man-made impacts on the climate system thus reflecting natural variability without the superimposed human forcings of more recent times. Improved knowledge of natural variability is a key factor for understanding the dynamics of man-made climate changes in particular.

Objective circulation analyses going further back in time than the last 150 years and based on objective pressure reconstructions have only been performed during the last few years. At first, studies on the NAO variability were increasingly extended into the historical past, back to 1864 by Hurrell (1995), to 1821 by Jones et al. (1997), to 1780 by Jacobeit et al. (1998), to 1675 and finally to 1500 by Luterbacher et al. $(1999,2002 b)$. Further circulation indices based on pressure differences were calculated, e.g. the EU index (Luterbacher et al. 1999) or zonal indices for Western (Slonosky et al. 2000) and Central Europe (Jacobeit et al. 2001a). Besides such simple indices analyses were increasingly based on the reconstructed large-scale pressure fields themselves, thus obtaining more sophisticated NAO indices from PCA studies (Pozo-Vázquez et al. 2000; Portis et al. 2001) and large-scale circulation patterns for the whole NorthAtlantic-European area (see Wanner et al. 1995 and Luterbacher et al. 2001, referring to the Late Maunder Minimum period). Long-term variability of European pressure fields was first investigated by Schmutz and Wanner (1998) applying a correlation-based classification to the former version of the reconstructed SLP grids from Jones et al. (1987). Referring to the enhanced reconstructions back to 1780 (Jones et al. 1999) further classifications based on EOF-clustering techniques and an objective Grosswettertyping were carried out by Beck (2000). Variability of EOF and PCA derived circulation patterns for the same period is discussed in several papers: Slonosky et al. (2000) produced patterns from the monthly SLP station series of the entire year, Jacobeit et al. (2001b) generated patterns for January and July from the reconstructed SLP grids. The latter study also looked at changes of these patterns themselves by comparing SLP composites between particular periods. Beck et al. (2001) additionally showed changes in Central European temperature and precipitation for subsamples defined by the occurrence of a particular circulation pattern, respectively.

In contrast to these studies this paper not only will extend the analysed period by using the most recent reconstructions back to the mid-17th century (Luterbacher et al. 2002a), but will also proceed in the consideration of dynamic aspects important for historical analyses. Thus, circulation variability will be examined not only with regard to frequency changes of major dynamical modes but also in terms of internal changes within each mode concerning both dynamic (vorticity, intensity) and climatic properties (temperature/precipitation during occurrence of each mode, respectively). All these aspects have to be taken into account for a better understanding of natural climate variability. Appropriate indices of circulation variability required for this extended analysis will be defined and discussed in the methods section.

\section{Data}

Circulation analyses are based on the monthly mean SLP fields objectively reconstructed by Luterbacher et al. (2002a) for the North-Atlantic-European area from $30^{\circ} \mathrm{N}$ to $70^{\circ} \mathrm{N}$ and from $30^{\circ} \mathrm{W}$ to $40^{\circ} \mathrm{E}$. These monthly reconstructions extend back to the year 1659 , further back (to 1500) only seasonally resolved SLP fields are available so far. Here we use an updated release with a $1^{\circ}$ spatial resolution, i.e. with 2911 grid points covering the study area.

The SLP grids have been reconstructed by means of an EOFregression technique with predictors comprising all available early instrumental time series as well as several climatic indices based on documentary proxy data (Pfister 1999; Glaser 2001) from various sites of Europe (see Luterbacher et al. 2002a for details and specifications). These indices have to be included since early instrumental pressure time series are sparsely distributed and, except for Paris and London (Slonosky et al. 2001b), do not start before the eighteenth century (1722 at Uppsala as the earliest date). As soon as station pressure predictors become available, these are by far the most important for SLP reconstructions explaining much more pressure variability than precipitation or temperature time series (Luterbacher et al. 2002a). But since temperature and precipitation have been involved in pressure reconstructions, SLP variability must not be used, to exclude circular arguments, for explaining historical climate variability. Indices of temperature and precipitation, however, may well be used for climatic characterisations of each circulation mode (see next section). This will be done by means of gridded data for temperature and precipitation similarly reconstructed for the continental areas of Europe (Luterbacher et al. submitted 2002). Climatic grids have been reconstructed only from temperature and precipitation predictors and will be available with a $0.5^{\circ}$ resolution according to the CRU grids from the twentieth century (New et al. 2000) used for model calibration.

Reconstructive skill for all these grids spatially and temporally varies depending on availability and quality of predictive data: in general, it increases with time, is better for winter than for summer, reaches its maximum around Central Europe and declines towards peripherical regions of the study area (Luterbacher et al. 2002a). From the mid-seventeenth century onwards, implying monthly grid resolutions, reconstructive skill should be sufficient for grids to be submitted to variability analyses on monthly to decadal time scales.

\section{Methods}

Studies of atmospheric circulation variability not only in terms of locally restricted indices but rather with respect to complete largescale pressure fields, require either well-defined categories of 
atmospheric states or dynamical modes of variability to have been derived. The former may be produced by classifying grids according to particular approaches, e.g. by correlation methods (Schmutz and Wanner 1998), EOF-clustering techniques (Jacobeit et al. 1998; Beck 2000; Luterbacher et al. 2001) or assignments of grids to predefined 'Grosswettertypes' (Beck 2000). Thus, each individual pressure field strictly arrives at just one of the pressure field classes with circulation variability being reflected in variations of frequency distributions among these classes. A major drawback of these approaches is the fact that strict boundaries between classes might separate individual fields with substantial correspondences, resulting in parts of the frequency changes only due to random pressure variations.

Derivation of dynamical modes of the atmospheric circulation is often based on various EOF techniques (e.g. Barnston and Livezey 1987), sometimes extended into a determination of lowdimensional regimes (Molteni et al. 1990; Corti et al. 1999) or coupled with climatic field variables in terms of canonical modes of variability (e.g. Beck 2000). This kind of analysis does not classify exclusively but rather gives multiple sets of continuous time coefficients for the identified modes which reproduce the original fields according to their varying weights.

In the present context $T$-mode principal component analysis (PCA) is the appropriate method since 341 monthly mean SLP grids for January and July, respectively, for 1659-1999 have to be analysed across 2911 grid points. The $T$-mode ensures a reasonable ratio between variables and cases by taking the SLP grids as the former, the grid points as the latter (Richman 1986). PCA implies that resulting eigenvectors are weighted by the square root of their eigenvalues. Thus, the weighted eigenvector components represent the correlation coefficients between original variables and the resulting principal components. In the $T$-mode they provide the time coefficients of the SLP modes whose spatial patterns are determined by the PC scores. Results are improved by orthogonal rotation (Richman 1986), and only those rotated PCs are retained having the greatest time coefficient among all the PCs for at least one of the original variables (i.e. there is at least one monthly SLP grid dominated by this mode).

This method has likewise been applied (Jacobeit et al. 2001b) to the monthly SLP grids reconstructed back to 1780 by Jones et al. (1999). In the former paper circulation variability has been described in terms of cumulative anomalies of PC time coefficients and of SLP composites referring to maximal differences within particular SLP patterns. In contrast to that, circulation variability for the extended period back to the mid-seventeenth century will be evaluated by means of newly defined running indices describing variations of PCA-derived SLP modes concerning their frequencies as well as dynamic and climatic properties of these modes:

a. The term 'frequency' is not strictly applicable to PCA-derived modes, their time coefficients rather indicate their relative importance within the original pressure fields. In order to disregard those cases with lower importance of a particular mode, we concentrate on those cases where its time coefficient is the leading one among all other coefficients for the same time. We might count these cases for a given time interval to produce a frequency term for the dominant incidence of this mode. However, this would also disregard the explicit information on varying importance expressed by the PC time coefficients. The most important part of this information is maintained by summing up all the leading time coefficients for a particular mode for a given time interval, thus constructing a weighted frequency term which represents the frequency of dominant incidence of this mode with each case weighted by the corresponding time coefficient. This sum of leading time coefficients will be determined for running 31-year periods (i.e. 1659-1689, $1660-1690, \ldots, 1969-1999)$ in order to reveal mode-incidence variability efficiently (shorter periods would increase zero-frequencies, longer periods would enhance smoothing).

b. Circulation modes not only change their incidence, but also their internal characteristics. An important one is the flow intensity depending on pressure gradients which may differ between different periods of incidence of the same circulation mode. Since flow configuration changes from one mode to another, pressure gradi- ents have to be determined between changing locations. For an index of intensity we calculate the pressure difference between the moving cores of the main centres of action depending on the dominant mode, respectively (e.g. for the zonal mode between the pressure maximum around the Azores and the minimum near Iceland, for the mode with an extended Russian High between this centre and its cyclonic counterpart above the Atlantic). To describe each mode's flow intensity for running 31-year periods as described, a weighted mean of pressure gradients is calculated from all months with the same dominant mode, respectively, inserting the leading time coefficients as weighting factors (i.e. the intensity from an individual mode incidence enters the index according to its relative importance).

c. Not only pressure gradients between centres of action, but also positions of these centres may vary within the same circulation mode thus modulating its flow pattern. This might significantly affect particular regions: for example, the mode of winter-time characterised by an Atlantic low-pressure system and an anticyclone over Russia (see later) will be linked with cold air advection from easterly directions towards Central or even Western Europe for westerly positions of these centres, whereas more easterly positions will imply warm air advection from westerly directions for the same regions in between. Even without a change in flow direction particular regions may be affected by spatial shifts of flow domains as in the case of mid-latitudinal Europe with increased cyclonic (anticyclonic) influence due to southward (northward) shifted westerlies within the zonal circulation mode (Jacobeit et al. 2001b).

To catch within-mode variations in flow patterns we refer to the relative vorticity given by

$\zeta=\delta v / \delta x-\delta u / \delta y$

with $u$ and $v$ as horizontal wind components along the zonal $(x)$ and meridional $(v)$ axes, respectively. Instead of approximating the partial derivatives $(\delta)$ of these wind components, a simple vorticity index has been defined based on the correlation coefficients between each monthly SLP grid within a spatially fixed subsection of the study area and an idealised cyclonic pressure distribution for this subsection (Beck 2000). This index varies between +1 and -1 according to the degree of cyclonicity or anticyclonicity within the actual SLP grids. The subsection to which this index refers has been fixed to the central area from $40^{\circ} \mathrm{N}$ to $60^{\circ} \mathrm{N}$ and from $10^{\circ} \mathrm{W}$ to $30^{\circ} \mathrm{E}$ thus reflecting most of the variations in flow patterns. To describe these variations for each circulation mode, weighted means of this vorticity index for running 31-year periods are calculated from all months with the same dominant mode, respectively, inserting the leading time coefficients as weighting factors (according to the preceding indices for frequency and intensity). Finally, the resulting time series for each mode are standardised to have a common scaling for the different variations of each mode concerning mean value and amplitude. Composite maps for each mode, based on months with standardised vorticity indices beyond +1 or -1 , respectively, will give an idea from the recorded variations within each mode occurring between these contrasting subtype patterns.

d. Variations within the same circulation mode not only do occur with respect to flow parameters (e.g. pressure gradient or relative vorticity), but also in relation to climatic characteristics: temperature and precipitation values experienced by a particular region during times with dominance of the same circulation mode will cover considerable ranges as might be indicated by widespread instationarities in the relationships between circulation and climatic indices (e.g. Osborn et al. 1999; Jacobeit et al. 2001a; Slonosky et al. 2001a; Pozo-Vázquez et al. 2001). Thus, the gridded temperature and precipitation data have been used to describe this variability by calculating areally weighted averages for a given region (in this case the continental grid boxes of Central Europe from $47^{\circ} \mathrm{N}$ to $54^{\circ} \mathrm{N}$ and from $6^{\circ} \mathrm{E}$ to $14^{\circ} \mathrm{E}$ ). From these mean values indices for each circulation mode and for each 31-year period have been averaged from all months with the same dominant mode, respectively, weighting each monthly value by the leading time coefficient of the corresponding circulation mode. Resulting variabilities are due to different influences: circulation characteristics varying within the 
same mode on the one hand (e.g. vorticity modulating precipitation), varying climatic boundary conditions on the other hand (e.g. changing SSTs modulating properties of advected air masses). To make a first guess concerning these different influences, the running indices for intensity and vorticity have been commonly regressed against the temperature and precipitation indices, respectively, giving shared variances $\left(r^{2}\right)$ between circulation and climate characteristics for particular circulation modes (to achieve a reasonable smoothing, these running regressions will be based on moving 60year periods). Unexplained variances, on the other hand, represent climatic influences independent from the dynamic parameters considered in this context.

\section{Results}

Analyses cover the period 1659-1999 thus reaching back to the Maunder Minimum, the coldest period within the Little Ice Age. Results will be discussed for the central month of winter (January) and summer (July), respectively.

\subsection{January}

\subsubsection{Circulation patterns}

$T$-mode PCA yields five circulation modes for January if those PCs are extracted which become the dominant mode at least for one January month during the 16591999 period. Two of them, however, are the dominant mode only for very few anomalous cases and will not be considered hereafter. The remaining three PCs account for some $90 \%$ of the original variance and thus represent the major circulation modes at sea-level for January. They will be designated by abbreviations pointing to distinct pattern characteristics (W: westerly flow pattern; L: central low pressure centre; RH: extended Russian High). Figure 1 gives typical SLP distributions for these modes: instead of ordinary PC patterns contrasting composites are shown for subsamples of SLP grids with the standardised vorticity index (see section 3 ) being beyond +1 or -1 , respectively (comprising some $30 \%$ of the original grids). These composites indicate the range in pattern configuration within the same circulation mode. The range for the RH mode, however, is not recorded adequately by this vorticity index due to an elevated degree of internal variability. Therefore, mode $\mathrm{RH}$ has been divided into two different patterns (easterly; westerly) defined by the contrasting sign of a zonal index (correlation coefficient of the actual SLP grid with an idealised pressure distribution for zonal westerlies, see Beck 2000) over the same central area for which the vorticity index has been determined (see Sect. 3). Thus, both patterns are associated with the same circulation mode, but are dealt with separately in the following analyses according to the different flow in the central part of the study area.

The first mode (W) accounting for $37.9 \%$ of the January SLP variance, represents the zonal circulation regime varying internally between the reproduced subtypes of Fig. 1a: the first one (left panel) with the subtropical high being restricted to the Azores region thus giving way for the westerlies to enter the whole midlatitudinal continent. The other subtype (right panel of Fig. 1a) includes high pressure extending into Central Europe thus diverting the westerlies towards higher latitudes over the British Isles and Scandinavia. The more our mode-dependent index of vorticity changes to positive (negative) values (see later), the more the actual flow configuration within mode $\mathrm{W}$ approaches the left (right) subtype pattern.

Mode $\mathrm{L}$ accounting for $25.6 \%$ of the original variance, depicts a strong Atlantic Low as the only major centre of action, deepening and retreating farther west in the second subtype (right panel) of Fig. $1 \mathrm{~b}$.

Mode RH, distinguished into easterly and westerly patterns with $8.5 \%$ and $17.6 \%$ of explained variance, respectively, represents a circulation regime with varying influence of a distinct Russian high. Among the easterly patterns, known for cold anomalies in central Europe, flow configurations vary between the subtypes of Fig. 1d: the first one (left panel) with the Russian High at more northern latitudes and a marked central Mediterranean Low, another one (right panel) with the highpressure influence extending towards Central and Western Europe. The westerly patterns (Fig. 1c), associated with increased temperatures in western parts of Europe, show an enhanced influence of the Atlantic Low pressure system modulated by the differently receding impact of the Russian High reflected in the two subtypes of Fig. 1c.

\subsubsection{Frequency variations}

The running frequency indices as explained in Sect. 3 are given in Fig. 2. The upper panel shows variations for the PCA-derived modes (i.e. without splitting mode RH into westerly and easterly patterns) indicating general antiphase variations between the zonal westerlies and the other two modes. Correlation coefficients $(\mathrm{W} / \mathrm{RH}$ and $\mathrm{W} / \mathrm{L})$ do not exceed moderate levels $(-0.61$ and -0.69 , respectively), but on long-term time scales periods of increased versus decreased frequencies approximate with phase shiftings of several decades, however, between modes $\mathrm{RH}$ and $\mathrm{L}$. Since the cyclical variations operate on multi-decadal time scales, the whole available period of 340 years is still too short for evaluating persistencies of these low-frequency cycles. Mode W, for example, just has three periods of enhanced importance: during the first half of the eighteenth century and around the beginnings of the nineteenth and twentieth centuries.

Remarkably, there were two periods when mode RH distinctly exceeded mode W (around the 1860s and the 1930s). The former period, however, coincides with positive anomalies in the NAO which started to accumulate during winter since the 1850s (Jacobeit et al. 
Fig. 1a-d Subtype composites (hPa) of January SLP modes 1659-1999. Left (right) panel: weighted means of those SLP grids with Central European standardised vorticity deviation index for each SLP mode being greater than +1 (lower than -1$)$

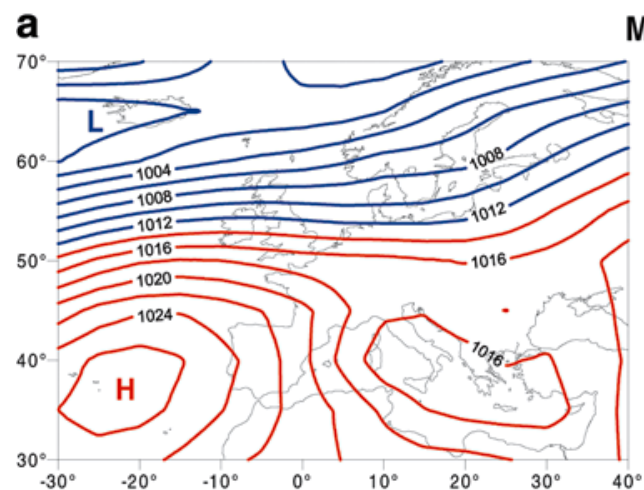

Mode W

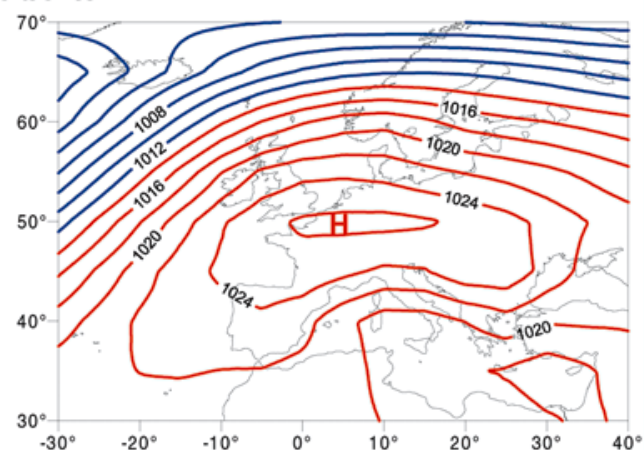

b

Mode L
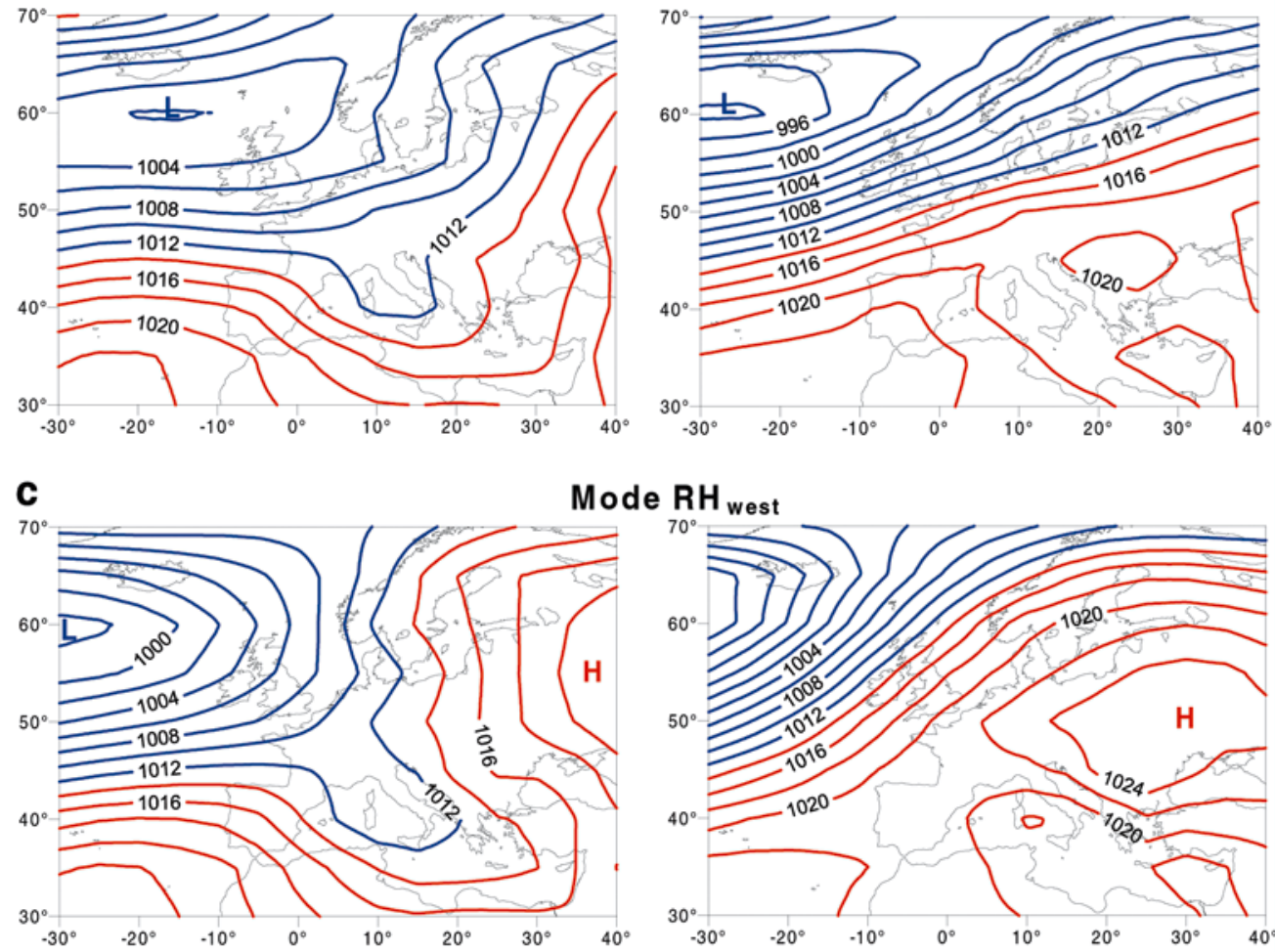

Mode $\mathbf{R H}_{\text {west }}$
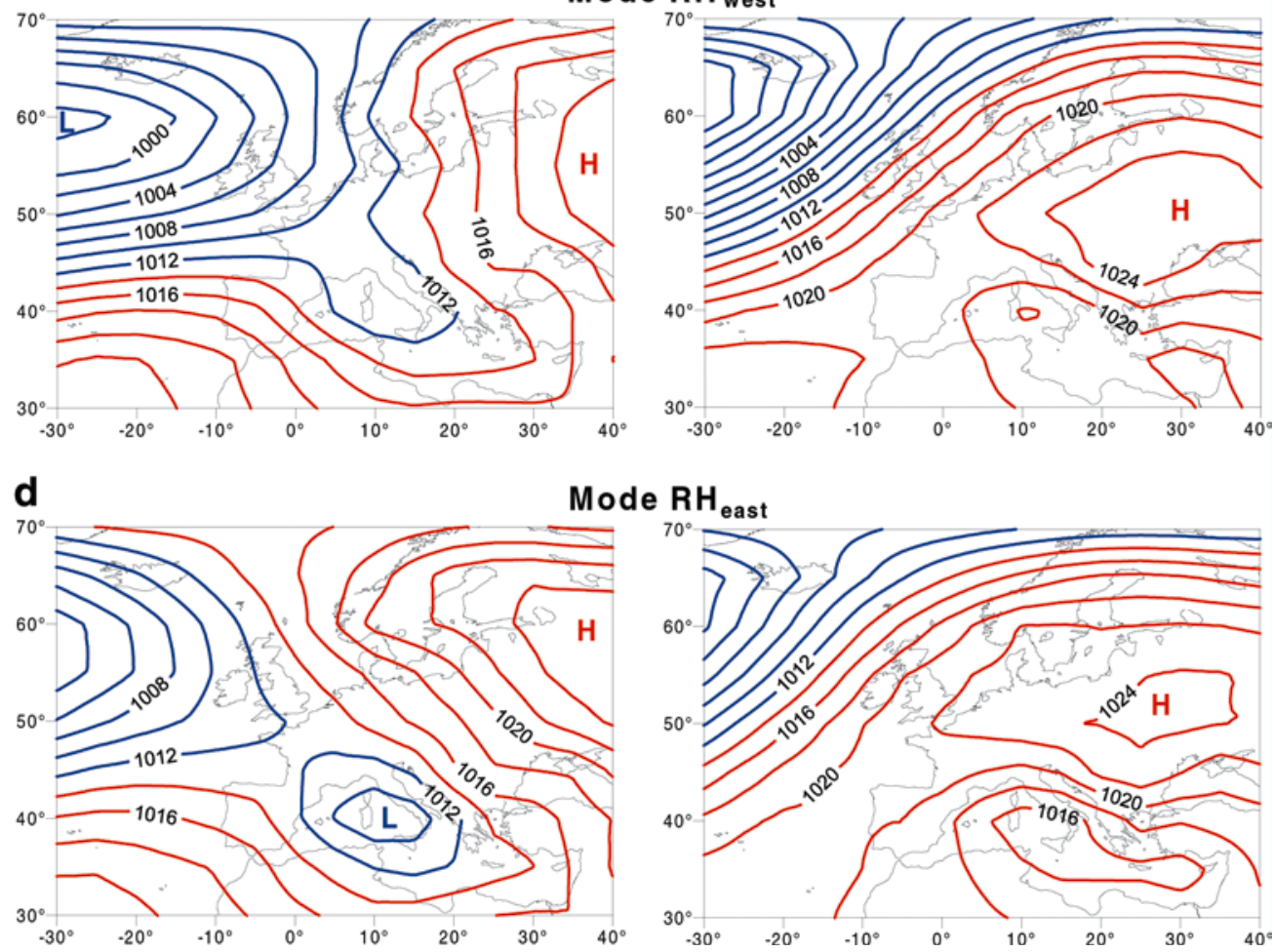

Mode $\mathbf{R H}_{\text {east }}$

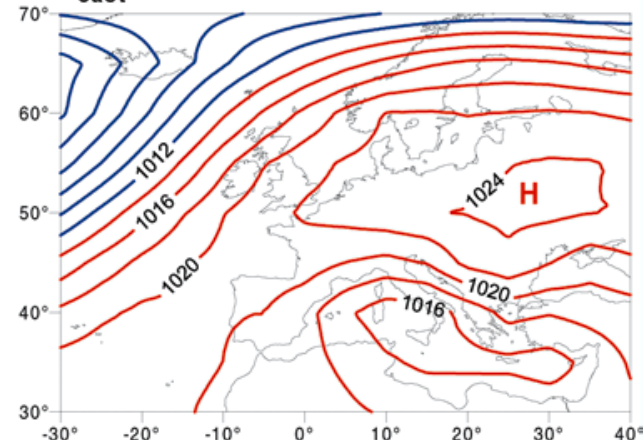

2001a). This seeming contradiction is resolved by the lower panel of Fig. 2 indicating that these RH maxima are due to the westerly pattern of this mode which generally dominates against the easterly pattern since the mid-nineteenth century. During earlier times, however,
$\mathrm{RH}_{\text {east }}$ also dominated for particular periods, especially during cold episodes of the Little Ice Age such as the Late Maunder Minimum around the turn of the eighteenth century (Luterbacher et al. 2001) or during the first half of the nineteenth century (Wanner et al. 2000). 
Thus, an important change in circulation is indicated for the mid-nineteenth century around the end of the Little Ice Age period.

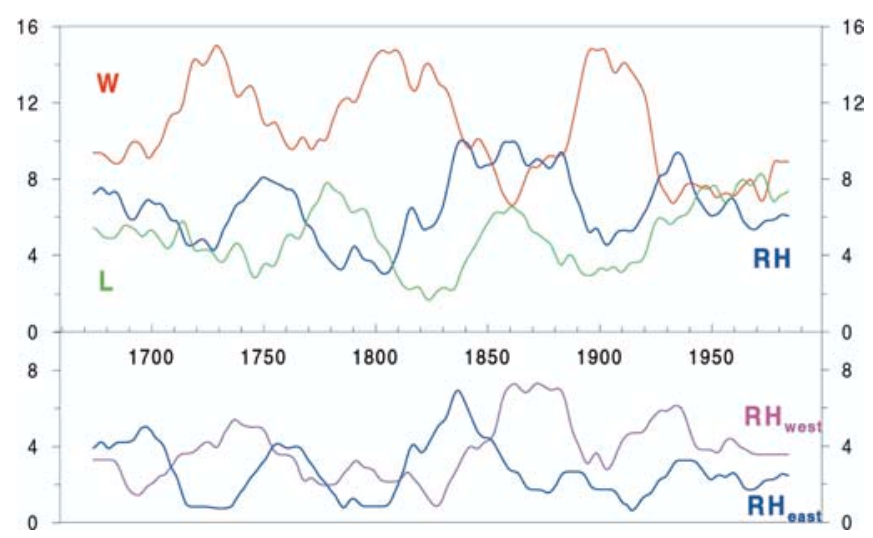

Fig. 2 The relative importance of January SLP modes since 1659 expressed as sums of leading time coefficients for moving 31-year periods (values are located at the centre of the corresponding period). The lower panel decomposes the time series for mode RH into subseries for its westerly and easterly patterns

\subsubsection{Within-mode variations}

The running indices describing variations in vorticity, intensity, temperature and precipitation for the particular SLP modes (see Sect. 3) are shown in Fig. 3. For mode W (Fig. 3a) all indices reached higher values during the twentieth century than most of the time before, i.e. the zonal circulation mode formerly occurred with less cyclonic vorticity, lower intensity, temperature and precipitation than during much of the last century. The main transitions, however, took place at different times: already starting around 1800 for intensity and temperature $(r=0.68)$ with the former reaching modern levels by the second half of the nineteenth century, the latter rapidly peaking around 1930 . At the same time vorticity and precipitation $(r=0.76)$ reached their first maxima after strongly increasing since the end of the nineteenth century. As a whole, long-term changes within mode W extended from a pronounced period around 1800 with below-average indices until the 1930s with above-average indices. The most recent development of the last few decades reveals decreasing vorticity implying a tendency towards northward shifted westerlies with increased
Fig. 3a-d Within-mode variations for January SLP modes since 1659 (weighted means for moving 31-year periods). Vort: standardised deviations of Central European relative vorticity. Int: pressure gradient $(\mathrm{hPa} / 1000 \mathrm{~km})$ between the mode-dependent centres of action. T: Central European temperature $\left({ }^{\circ} \mathrm{C}\right)$ during occurrence of the specified SLP mode. $R$ : Central European precipitation $(\mathrm{mm})$ during occurrence of the specified SLP mode. Central lines represent the long-term averages (1659-1999), respectively. Standard deviations of all parameters are equally scaled on the vertical axes a

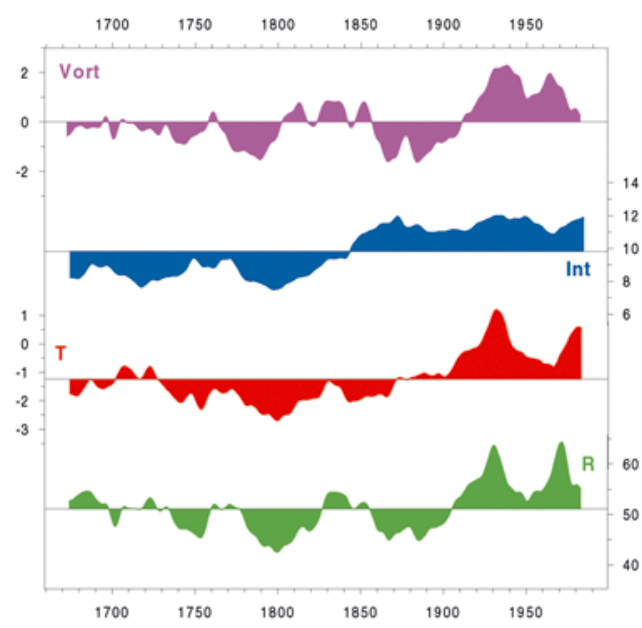

C

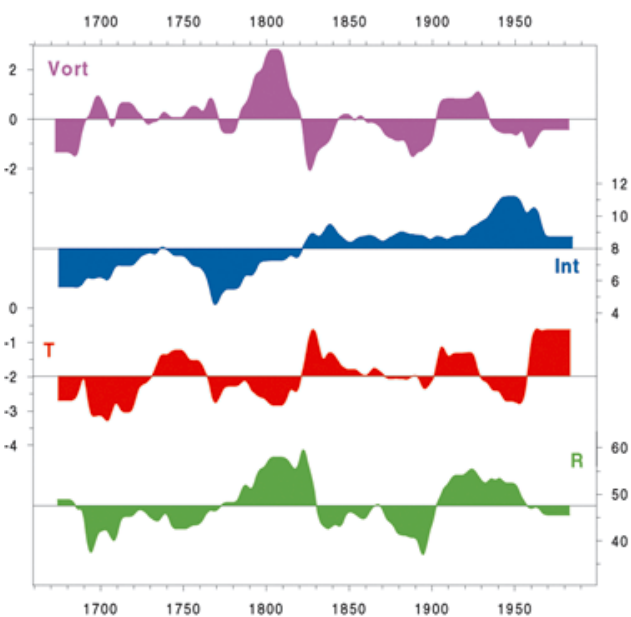

b

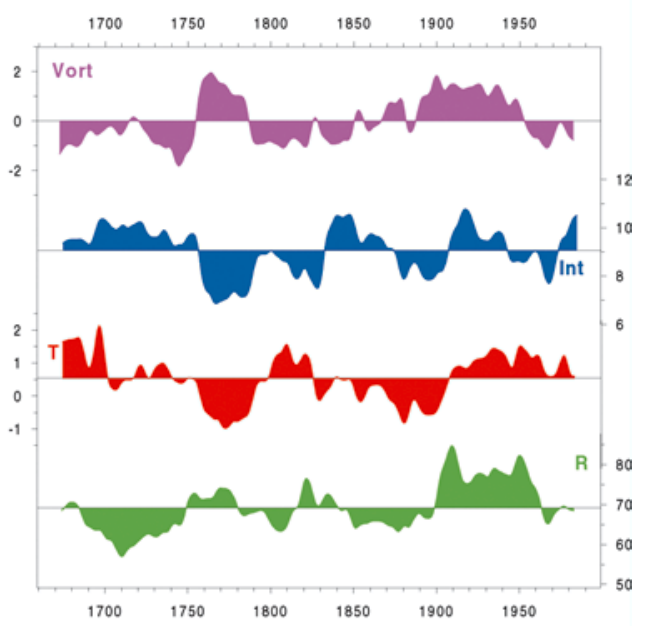

d

January Mode $\mathbf{R H}_{\text {east }}$

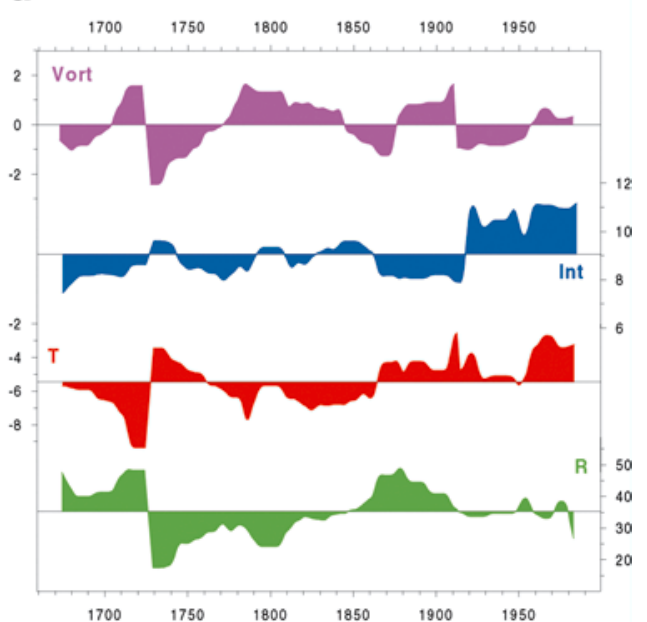


anticyclonicity to the south as already reported for the Alpine region by Wanner et al. (2000). However, this recent shift maintains increasing values for intensity and temperature in contrast to earlier times.

Within-mode changes do not merely reflect general changes in climatic boundary conditions but may well differ between different circulation modes. This becomes evident when looking at the westerly pattern of mode RH (Fig. 3c) where only the intensity index reveals a significant tendency to increase towards the mid-twentieth century. The weak trends towards higher temperatures (across the whole period) and more anticyclonic subtypes (since $\sim 1800$ ) are not statistically significant and superimposed by decadal-scale variations of different amplitudes and wavelengths. However, comparing the indices of Fig. 3c for the last two periods of maximum frequency (see Fig. 2) clearly indicates that all of them had higher values during the first decades of the twentieth century than during the second half of the nineteenth century. However, this increase was not part of systematic long-term changes as revealed for mode W. More prominent are various anomaly periods with the most important one around 1800 when the maximum of cyclonic subtypes was reached, linked with elevated precipitation amounts and, unlike the linkage for mode $\mathrm{W}$, with below-average temperatures in Central Europe.

For the easterly pattern of mode RH (Fig. 3d) such anomaly periods (discernible by maxima or minima in the vorticity index) coincide with reduced frequencies, thus being based on just a few particular cases, which will not be discussed further. However, there are some distinct tendencies in the climatic parameters: a sustained warming of mode $\mathrm{RH}_{\text {east }}$ across the nineteenth century as well as a wetness increase which started some 50 years earlier, but changed to a downward trend during the 1870s. This evolution clearly contrasts with mode W (Fig. 3a) thus indicating that the general increase in Central European winter precipitation during the last century (Beck et al. 2001) does not apply to each mode's typical precipitation amounts. A common feature of modes $\mathrm{W}$ and $\mathrm{RH}_{\text {east }}$, however, are the higher pressure gradients of recent times compared with the whole of the earlier period.

This does not apply to mode $\mathrm{L}$ whose modern intensity still varies around medium values (Fig. $3 \mathrm{~b}$ ). However, long-term periods may be discerned with respect to vorticity subtypes developing a pronounced cyclonic maximum during the second half of the eighteenth century, falling afterwards to enter a sustained reincrease during the nineteenth century and proceeding to the modern evolution towards less cyclonic conditions. These long-term variations are inversely reflected by the thermal evolution of mode $\mathrm{L}$ resulting in some clear-cut anomaly periods with pronounced cyclonicity, enhanced precipitation and, related to mean values of mode $\mathrm{L}$, below-average temperatures in Central Europe: most conspicuously after 1750 , somewhat less striking around 1900. Thus, warm advection from the southwest is rather linked with more anticyclonic subtypes whereas enhanced cyclonic conditions imply the overturning of different air masses.

\subsection{July}

\subsubsection{Circulation patterns}

One of the five PCs extracted becomes the dominant mode for only very few July months. Thus, the July circulation may be described by four principal modes of variation explaining some $97 \%$ of the original variance. Once more, abbreviations should point to distinct pattern characteristics (W: westerly flow pattern; $\mathrm{CY}$ : major cyclonic centre; AR: Atlantic ridge pattern; CR: continental ridge pattern). Figure 4 shows typical pressure distributions for these modes in terms of composites for subsamples of SLP grids with the standardised vorticity index being beyond +1 or -1 , respectively (comprising some $30 \%$ of the original grids).

Mode $\mathrm{W}$ accounting for $28.1 \%$ of the original variance represents a summer zonal circulation varying between opposite subtypes (Fig. 4a): a stronger subpolar low with restrained anticyclonic influence to its south (left panel), and a weakened low near Iceland with a zonal ridge of high pressure extending across central Europe (right panel). Mode CY (26.4\% of explained variance) shows similar behaviour with the cyclonic centre of action, however, being located farther eastward over Northern Europe for both subtypes (Fig. 4b).

The following modes of July extend anticyclonic circulations towards higher latitudes: mode AR $(23.9 \%$ of explained variance) with a strong ridge from the Azores towards the northeast including subtypes of different extension between the North Sea and the Baltic region (Fig. 4c); mode CR (18.9\% of explained variance) with high pressure over Fennoscandia as part of an anticyclonic domain over the continent including subtypes with different regional prevalence between Northern and Central Europe (Fig. 4d).

\subsubsection{Frequency variations}

Most outstanding in Fig. 5 is the unique maximum of mode $\mathrm{W}$ at the end of the eighteenth century. In contrast to common suggestions this did not coincide with Central European summer temperatures below, but rather distinctly above the long-term average during this period (Jacobeit et al. 1998; Beck 2000) thus pointing to important changes within this mode discussed later.

Mode AR, in contrast, was at its minimum around the 1790s and underwent a long-term increase to its recent maximum whereas mode CY dropped to its minimum during the last few decades. This means a general shift towards anticyclonic steering over the western part of the European continent with its major development occurring since the mid-twentieth century as an 
Fig. 4a-d Subtype composites (hPa) of July SLP modes 1659 1999. Left (right) panel: weighted means of those SLP grids with Central European standardized vorticity deviation index for each SLP mode being greater than +1 (lower than -1$)$

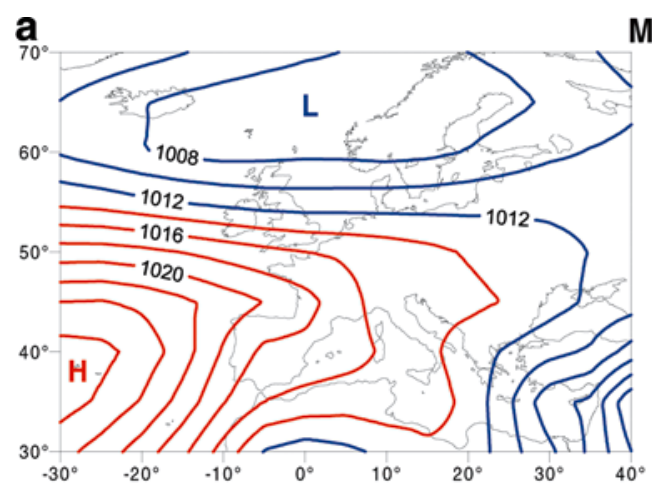

Mode W

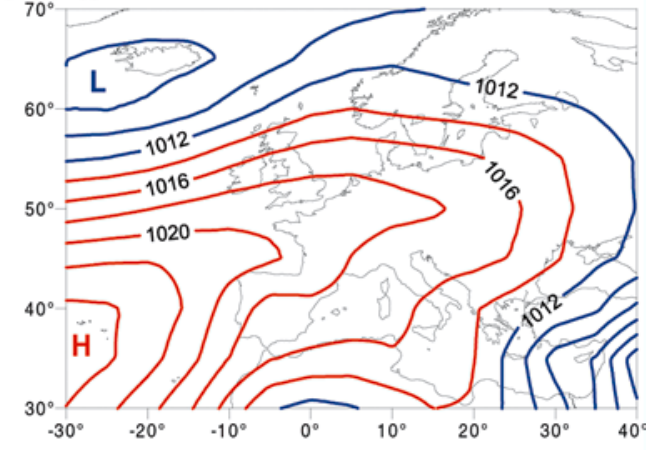

Mode CY
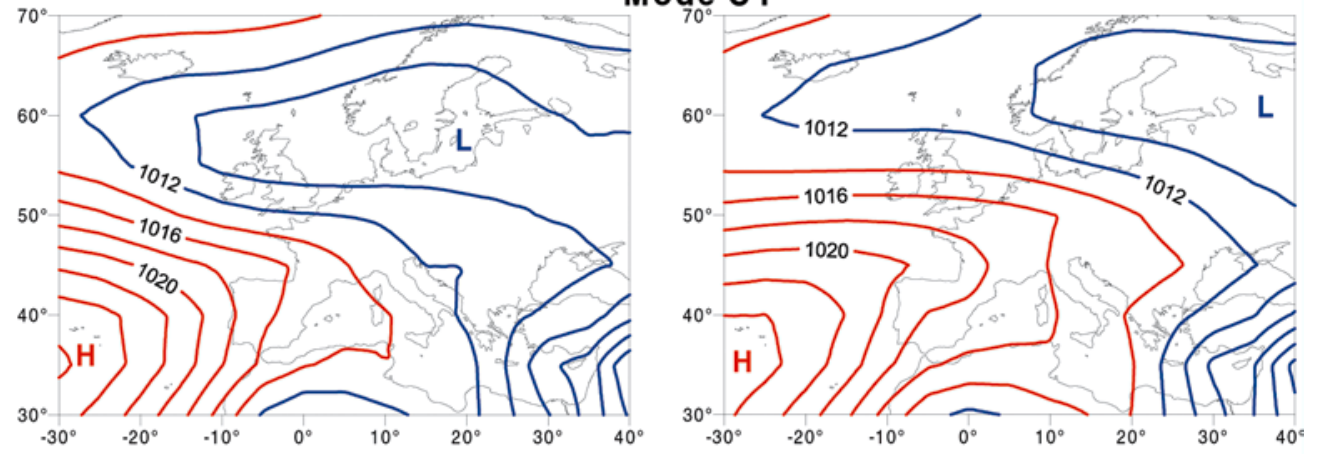

Mode AR
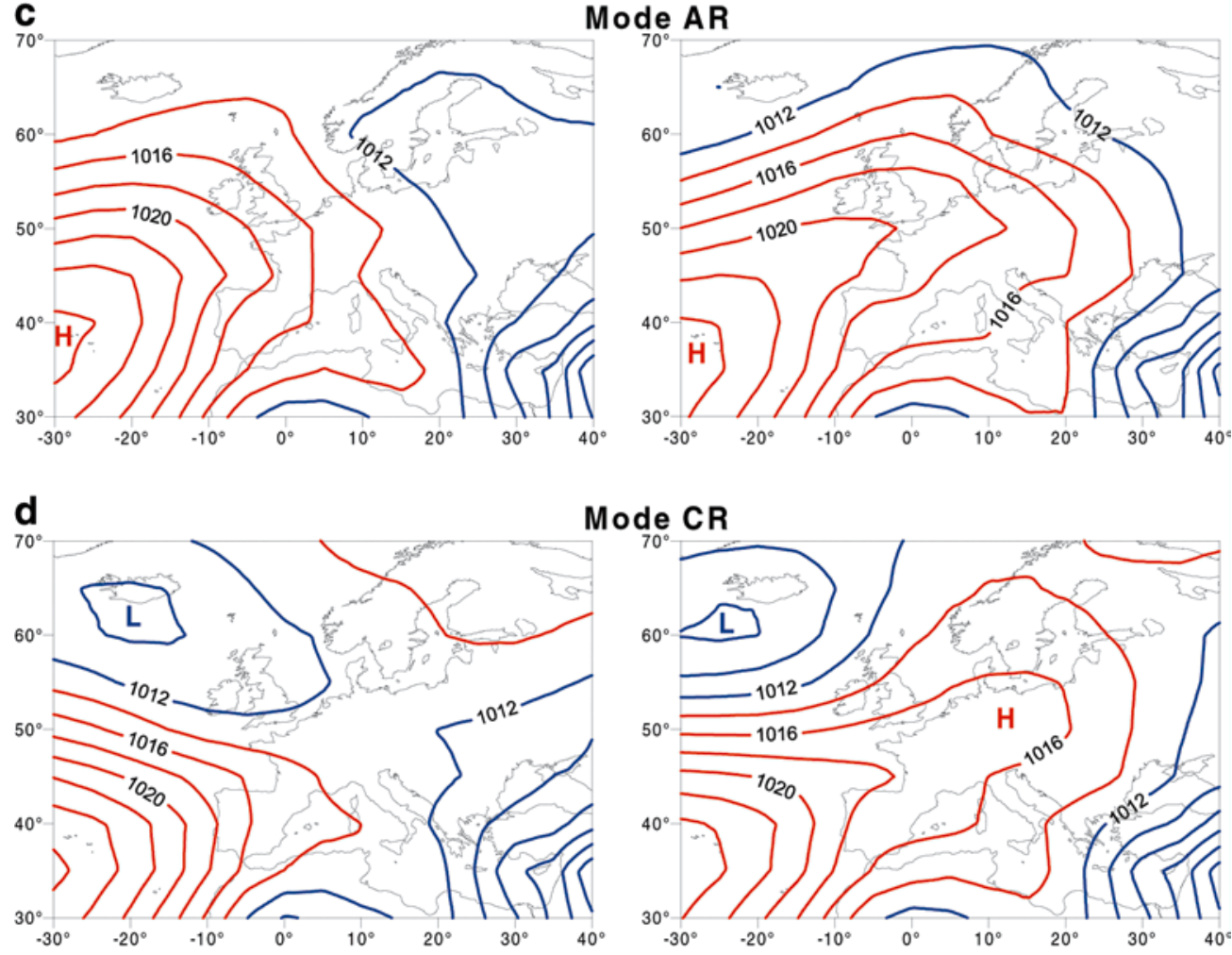

Mode CR

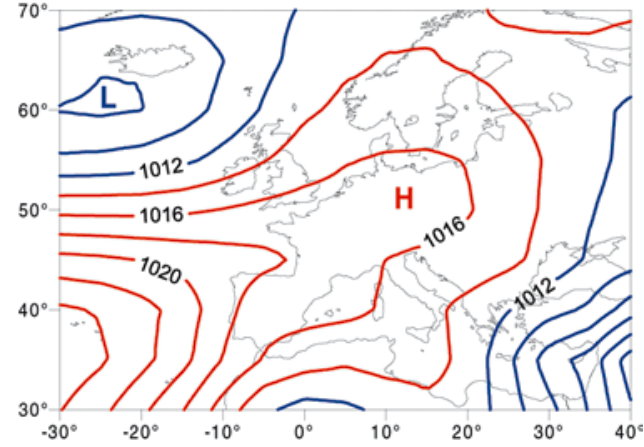

extraordinary phenomenon during the last 340 years (Fig. 5). Periods with more pronounced cyclonic character repeatedly occurred during the historical past: around the end of the nineteenth century, around the 1830s and especially during the first half of the eighteenth century when a distinct maximum of mode CY coincided with the falling-off of mode CR (Fig. 5). Its preceding maximum, however, only has restricted 
validity since the reconstruction skill of gridded SLP during summer is still rather poor at least until the end of the seventeenth century (Luterbacher et al. 2002a).

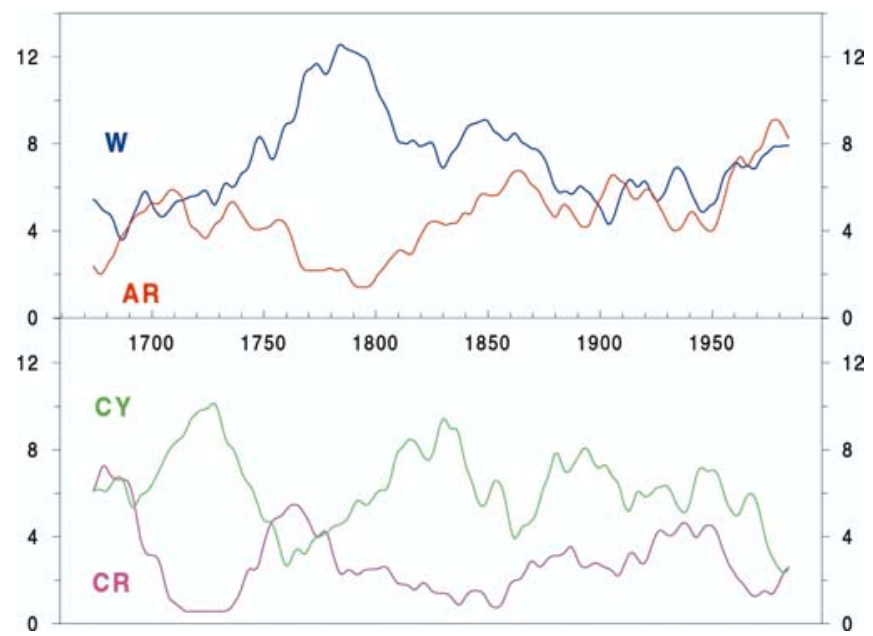

Fig. 5 The relative importance of July SLP modes since 1659 expressed as sums of leading time coefficients for moving 31-year periods (values are located at the centre of the corresponding period)

\subsubsection{Within-mode variations}

For mode W (Fig. 6a) distinct antiphase correlations are evident between the vorticity parameter and both intensity $(r=-0.68)$ and Central European pattern temperature $(r=-0.74)$. Relationships with pattern precipitation are more variable due to independent variations in specific humidity and convective activity. Most prominent are several anomaly periods: on the one hand characterised by cyclonic subtypes with below-average temperatures such as during the first half of the eighteenth century or, less pronounced, around 1850 and 1900 . On the other hand, the reverse case has its most distinct occurrence at the end of the eighteenth century. This was just the time with increased frequency of mode W (see Fig. 5) coinciding with the period mentioned of marked summer warmth in Central Europe. This warmth was obviously not due to increased frequencies of modes AR or CR, but rather linked to anticyclonic patterns of mode W (Fig. 4) with strengthened pressure gradients to the north. These conditions contributed to the elevated temperatures indicated for mode $\mathrm{W}$ around this period (Fig. 6a).

Most outstanding for mode CY is the strong cyclonic anomaly linked with increased precipitation at the
Fig. 6a-d Within-mode variations for July SLP modes since 1659 (weighted means for moving 31-year periods). Abbreviations as in Fig. 3
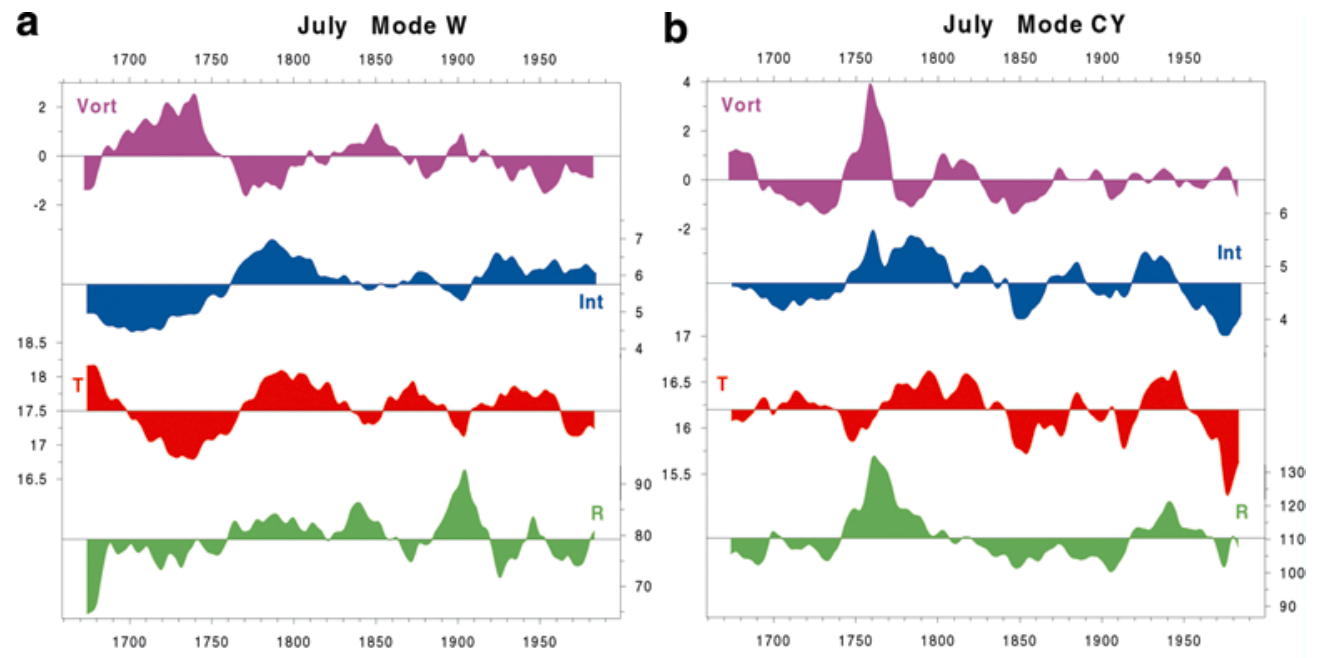

C
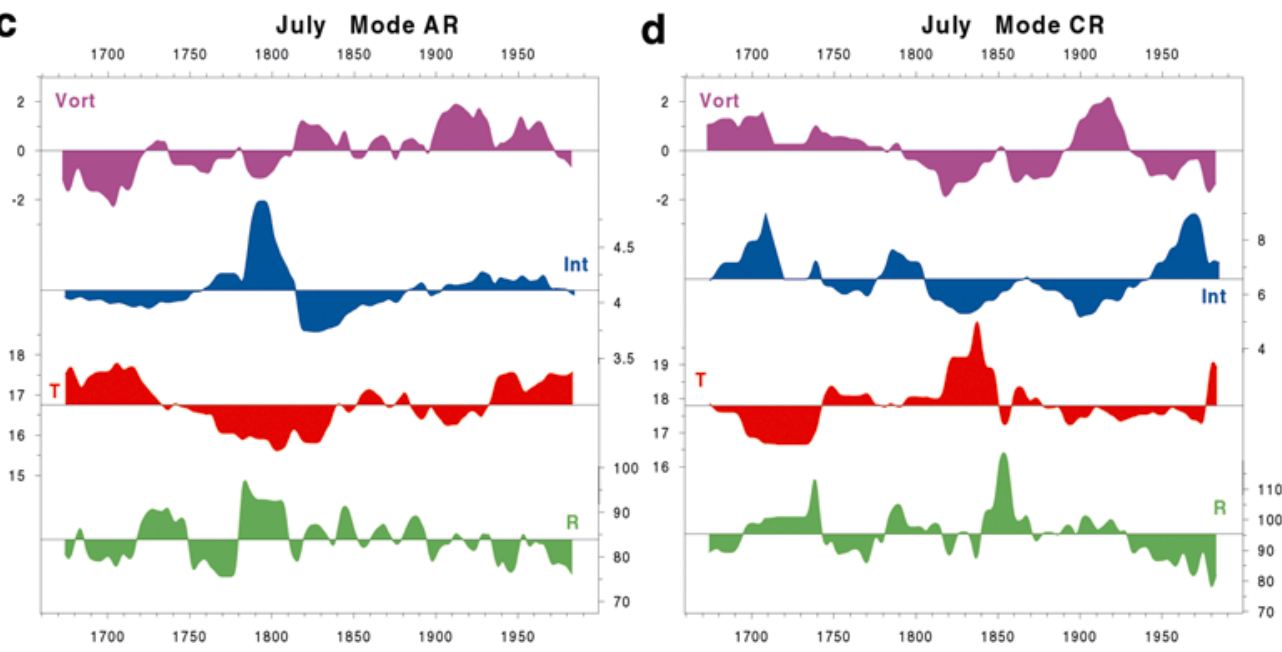
beginning of the second half of the eighteenth century (Fig. 6b). During this time, however, mode CY passed through a frequency minimum (Fig. 5) whereas the preceding maximum was rather linked with anticyclonic subtype preferences (Fig. 6b). Remarkably, the recent decline in frequency of mode CY since the 1950s is accompanied by unique declines of its intensity and temperature until the closing decades of the twentieth century.

The striking intensity anomaly of mode AR (Fig. 6c) at the end of the eighteenth century becomes less important in view of the simultaneous frequency minimum (Fig. 5) whereas the pronounced anticyclonic conditions with elevated temperatures and reduced precipitation at the beginning of the eighteenth century occurred with increased frequency. From this period onward until the first half of the twentieth century a long-term trend towards cyclonic subtypes was superimposed upon the decadal variability in the vorticity parameter (Fig. 6c) changing to the opposite trend (decreasing vorticity) during the period of increasing AR frequency since the 1950s (Fig. 5). The internal warming of mode AR after the eighteenth century's cooling was only interrupted around 1900 roughly concomitant with a marked vorticity increase (Fig. 6c).

For mode CR most of the index maxima and minima of Fig. 6d coincide with rather low frequencies (Fig. 5), the twentieth century still showing the most coherent tendencies: towards anticyclonic subtypes with distinctly declining precipitation, towards higher intensity which only drops again with the rather late internal warming.

\section{Discussion and conclusions}

Atmospheric circulation modes derived for the last 340 years by multivariate analyses of reconstructed SLP grids generally correspond to modes already determined by similar analyses extending back to the end of the eighteenth century (Slonosky et al. 2000; Jacobeit et al. 2001b; Beck et al. 2001). A major advance in this study on past circulation variability, however, has been achieved by considering not only frequency variations (Figs. 2 and 5), but also internal changes within these modes. In contrast to Jacobeit et al. (2001b) who showed such changes only for selected periods during the past two centuries, within-mode variability is documented continuously throughout the past 340 years in Figs. 3 and 6. Furthermore, these figures not only refer to mode-dependent temperature and precipitation characteristics as outlined by Beck et al. (2001) for SLP patterns since 1780, but also include indices of within-mode variability in pressure gradients and relative vorticity. Thus, variations between contrasting subtypes for each mode (Figs. 1 and 3) could be continuously identified since the mid-seventeenth century.

Internal variations within particular circulation modes are major dynamical factors in the context of historical climatic changes. This may be seen from the results for the zonal circulation mode in January. Since frequency changes rather occurred as fluctuations on multi-decadal time scales (Fig. 2), the climate transition from the Little Ice Age to the following period proceeded mainly by way of long-term within-mode changes (Fig. 3a). Some of these had already started by 1800 , increasing pressure gradients and rising mode-W-temperature, whereas mode-W-precipitation and relative vorticity dropped once more during the second half of the nineteenth century before increasing distinctly afterwards. The whole within-mode transition concluded around 1930 when all parameters had reached well above-average values.

Further evidence refers to the January mode RH characterised by a Russian High of variable extension to the west. Based on the time coefficient of a corresponding EOF derived from SLP data since 1774, Slonosky et al. (2000) refer to a period of more intense meridional circulation from 1822 to 1870 . This seems also to be indicated by RH frequencies exceeding those of mode $\mathrm{W}$ around the mid-nineteenth century (Fig. 2, upper panel). Further information, however, depicts that just within this 'meridional period' important changes took place around 1850: from dominating easterly to dominating westerly patterns of mode RH (Fig. 2, lower panel), concomitant with a major turning point in the long-term evolution of cumulative NAO anomalies from negative to positive predominances (Jacobeit et al. 2001a). This turning point is also reflected in the transition of mode $\mathrm{W}$ intensities from below- to above-average values around the mid-nineteenth century (Fig. 3a). At the same time the reorganisation of the atmospheric circulation towards the end of the Little Ice Age implied prevailingly eastward shifted positions within mode RH leading to a predominance transition from easterly to westerly patterns.

The main long-term evolution during July may be seen as a general increase of anticyclonic conditions during the last two centuries indicated by opposite frequency changes of modes AR and CY (Fig. 5) and by general shifts towards anticyclonic subtypes (Fig. 6) for modes $\mathrm{W}$ (since the mid-nineteenth century), CR and AR (during the last 80 and 50 years, respectively). Mode CY maintains the highest rainfall index, but declines in frequency. The generally rising anticyclonicity is also reflected within the European trend atlas 1891-1990 (Schönwiese et al. 1993) showing increasing pressure for Central Europe during July. Opposite conditions prevailed during the first half of the eighteenth century (a strong frequency maximum of mode $\mathrm{CY}$ and preferred cyclonic subtypes of mode $\mathrm{W}$ ) before a distinct anomaly period occurred towards the end of the eighteenth century with a striking frequency maximum of mode $\mathrm{W}$ preferring anticyclonic subtypes at the same time (Figs. 5 and 6a). This within-mode variation, however, is not yet able to explain major parts of the elevated mode$\mathrm{W}$-temperatures around this time which is known from 

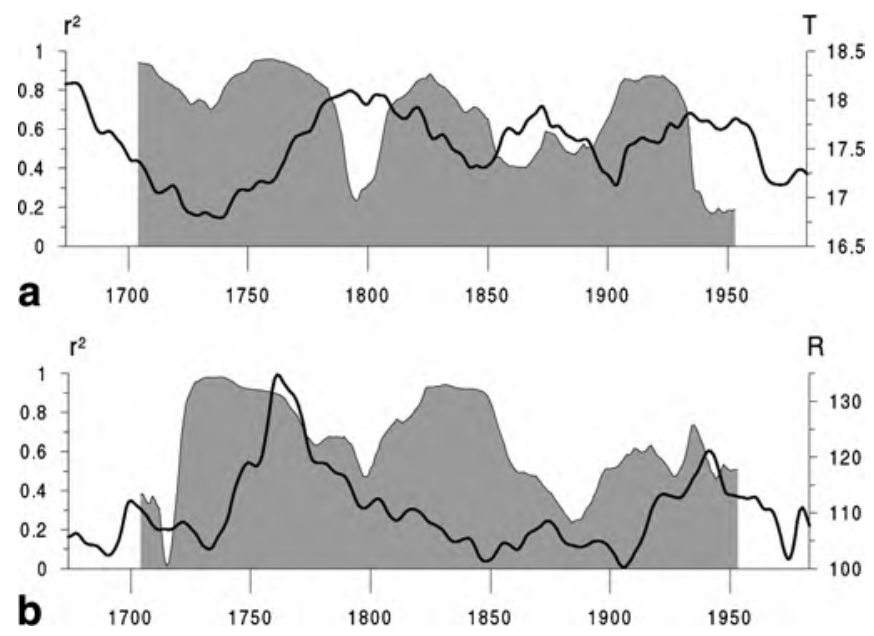

Fig. 7a, b Variances of $T$ (a, bold line) and $R$ (b, bold line), respectively, explained for moving 60 -year periods by vorticity and intensity parameters (multiple $r^{2}$, grey areas) of a July SLP mode W; b July SLP mode CY. T: Central European temperature $\left({ }^{\circ} \mathrm{C}\right)$ of July SLP mode W. $R$ : Central European precipitation ( $\mathrm{mm}$ ) of July SLP mode CY

independent data as a period of marked summer warmth in Central Europe (Beck 2000). Figure 7a clearly shows that variances of mode-W-temperature explained by variations of circulation parameters just broke down during this period. This means that climatic boundary conditions independent from variations within mode $\mathrm{W}$ additionally favoured higher summer temperatures around the turn of the eighteenth century.

Thus, in general, mode-dependent variations of climatic parameters have to be distinguished into one part explained by varying circulation characteristics, and another part due to varying climatic boundary conditions. Both parts change with time (Fig. 7a) and differ between modes. Another example referring to precipitation changes within mode CY (Fig. 7b) reveals that they are mostly well explained by changes of vorticity and intensity, including the strong cyclonic anomaly at the beginning of the second half of the eighteenth century.

A final look at present conditions in view of the variations since the mid-seventeenth century reveals that only a few of the recent circulation phenomena may be really unusual or unprecedented. Even the strong increase in the winter-time westerly circulation during the last decades does not appear extraordinary considering the low-frequency cycle indicated for mode $\mathrm{W}$ in January (Fig. 2): if this natural variation on the time scale of 80-100 years should continue, a further increase of mode $\mathrm{W}$ during the forthcoming decades may be expected independently from man-made impacts due to the enhanced greenhouse forcing (note that final values of Fig. 2 represent the period from the late 1960s to the late $1990 \mathrm{~s}$ when zonal circulation just proceeded from below- to well above-average values). Unusual conditions, however, are indicated recently for some mode-W-parameters (Fig. 3a): despite the tendency of decreasing vorticity during the last few decades, temperature and intensity continue to increase indicating a warming also of subtypes with rising anticyclonicity above southern Central Europe. This evolution reverses the positive relation between vorticity and temperature for January mode $\mathrm{W}$ and defines novel conditions within the last 340 years.

During July, the long-term evolution of increasing anticyclonicity has strengthened during the last 50 years becoming recently a unique phenomenon within the last centuries, as may be seen from the diverging frequency changes of modes CY and AR (Fig. 5) and from the distinctly declining precipitation values of mode CR (Fig. 6d). Together with recently preferred anticyclonic subtypes of mode W (Fig. 6a) this caused an unprecedented decline in Central European July precipitation during the second half of the twentieth century (Beck et al. 2001).

Circulation analyses based on reconstructed SLP grids for several centuries may be extended to further investigations, too, e.g. to dynamic studies on regional climate variability as far as SLP data independent from climatic predictors are available (Beck et al. 2001). Another approach recently applied by Sturm et al. (2001) and Wanner et al. (submitted, 2002) refers to relationships between historical flood events and atmospheric circulation modes. This kind of analysis directs dynamic studies even towards the social impacts of extreme events.

Acknowledgements This work has been supported by the German Science Foundation (DFG) under grant JA 831 and by the Swiss National Science Foundation (SNSF) under grant number 11-52786-97 as well as by the National Centre of Competence in Research (NCCR) in Climate funded by SNSF.

\section{References}

Appenzeller C, Stocker TF, Anklin M (1998) North Atlantic Oscillation dynamics recorded in Greenland ice cores. Science 282: 446-449

Bärring L, Jönsson P, Achberger C, Ekström M, Alexandersson H (1999) The Lund instrumental record of meteorological observations: reconstruction of monthly sea-level pressure 17801997. Int J Climatol 19: 1427-1443

Barnston AG, Livezey RE (1987) Classification, seasonality and persistence of low frequency atmospheric circulation patterns. Mon Weather Rev 115: 1083-1126

Beck C (2000) Zirkulationsdynamische Variabilität im Bereich Nordatlantik-Europa seit 1780. Würzburger Geographische Arbeiten 95, pp 350

Beck C, Jacobeit J, Philipp A (2001) Variability of North-AtlanticEuropean circulation patterns since 1780 and corresponding variations in Central European climate. In: Brunet-India M, López-Bonillo D (eds) Detecting and modelling regional climate change. Springer, Berlin Heidelberg New York, pp 321332

Cook ER, D'Arrigo RD, Briffa KR (1998) The North Atlantic Oscillation and its expression in circum-Atlantic tree-ring chronologies from North America and Europe. The Holocene 8: 9-17

Cook ER, D'Arrigo RD, Mann M (2002) A well-verified, multiproxy reconstruction of the winter North Atlantic Oscillation Index since AD 1400. J Clim 15: 1754-1764 
Cullen HM, D'Arrigo RD, Cook ER, Mann M (2000) Multiproxy reconstructions of the North Atlantic Oscillation. Paleoceanography 16: 27-39

Corti S, Molteni F, Palmer TN (1999) Signature of recent climate change in frequencies of natural atmospheric circulation regimes. Nature 398: 799-802

Garcia R, Gimeno L, Hernandez E, Prieto R, Ribera P (2000) Reconstructing the North Atlantic atmospheric circulation in the 16th, 17th and 18th centuries from historical sources. Clim Res 14: 147-151

Glaser R (2001) Klimageschichte Mitteleuropas. 1000 Jahre Wetter, Klima, Katastrophen. Wiss. Buchgesellschaft, Darmstadt, pp 227

Glueck MF, Stockton CW (2001) Reconstruction of the North Atlantic Oscillation, 1429-1983. Int J Climatol 21: 1453-1465

Hurrell JW (1995) Decadal trends in the North Atlantic Oscillation: regional temperatures and precipitation. Science 269: 676679

Jacobeit J, Beck C, Philipp A (1998) Annual to decadal variability in climate in Europe - objectives and results of the German contribution to the European climate research project ADVICE. Würzburger Geographische Manuskripte 43, pp 163

Jacobeit J, Wanner H, Koslowski G, Gudd M (1999) European surface pressure patterns for months with outstanding climatic anomalies during the sixteenth century. Clim Change 43: 201221

Jacobeit J, Jönsson P, Bärring L, Beck C, Ekström M (2001a) Zonal indices for Europe 1780-1995 and running correlations with temperature. Clim Change 48: 219-241

Jacobeit J, Jones PD, Davies TD, Beck C (2001b) Circulation changes in Europe since the 1780s. In: Jones PD, Ogilvie A, Davies TD, Briffa KR (eds) History and climate: memories of the future? Kluwer, New York, pp 79-99

Jones PD, Wigley TM, Briffa KR (1987) Monthly mean pressure reconstruction for Europe (back to 1780) and North-America (back to 1858). DOE Technical Report TR37, US Department of Energy, Washington D.C., pp 99

Jones PD, Jonsson T, Wheeler D (1997) Extension of the North Atlantic Oscillation using early instrumental pressure observations from Gibraltar and southwest Iceland. Int J Climatol 17: $1433-1450$

Jones PD, et al (1999) Monthly mean pressure reconstruction for Europe 1780-1995. Int J Climatol 19: 347-364

Kalnay E, et al (1996) The NCEP/NCAR 40-Year Reanalysis Project. Bull Am Meteorol Soc 77: 437-471

Kington JA (1988) The weather of the 1780s over Europe. Cambridge University press, Cambridge, UK, pp 166

Kistler R, et al (2001) The NCEP-NCAR 50-year Reanalysis: monthly means CD-ROM and documentation. Bull Am Meteorol Soc 82: 247-267

Lamb HH, Johnson AI (1966) Secular variations of the atmospheric circulation since 1750. Geophys Mem 110, pp 125

Luterbacher J, Schmutz C, Gyalistras D, Xoplaki E, Wanner H (1999) Reconstruction of monthly NAO and EU indices back to AD 1675. Geophys Res Lett 26: 2745-2748

Luterbacher J, Rickli R, Xoplaki E, Tinguely C, Beck C, Pfister C, Wanner H (2001) The Late Maunder Minimum (1675-1715) a key period for studying decadal scale climatic change in Europe. Clim Change 49: 441-462

Luterbacher $\mathbf{J}$, et al (2002a) Reconstruction of sea level pressure fields over the eastern North Atlantic and Europe back to 1500. Clim Dyn 18: 545-561

Luterbacher J, Xoplaki E, Dietrich D, Jones PD, Davies TD, Portis D, Gonzalez-Rouco JF, von Storch H, Gyalistras D, Casty C,
Wanner H (2002b) Extending North Atlantic Oscillation reconstructions back to AD 1500. Atmos Sci Lett 2: 114-124

Molteni F, Tibaldi S, Palmer TN (1990) Regimes in the wintertime circulation over northern extratropics. I: observational evidence. Q J R Meteorol Soc 116: 31-67

New M, Hulme M, Jones PD (2000) Representing twentieth century space-time climate variability. II: development of 19011998 monthly grids of terrestrial surface climate. J Clim 13: 2217-2238

Osborn TJ, Briffa KR, Tett SFB, Jones PD, Trigo RM (1999) Evaluation of the North Atlantic Oscillation as simulated by a coupled climate model. Clim Dyn 15: 685-702

Pfister C (1999) Wetternachhersage. 500 Jahre Klimavariationen und Naturkatastrophen 1496-1995. Bern Stuttgart Wien, pp 304

Portis DH, Walsh JE, El Hamly M, Lamb PJ (2001) Seasonality of the North Atlantic Oscillation. J Clim 14: 2069-2078

Pozo-Vázquez D, Esteban-Parra MJ, Rodrigo FS, Castro-Diez Y (2000) An analysis of the variability of the North Atlantic Oscillation in the time and the frequency domains. Int $\mathbf{J}$ Climatol 20: $1675-1692$

Pozo-Vázquez D, Esteban-Parra MJ, Rodrigo FS, Castro-Diez Y (2001) A study of NAO variability and its possible non-linear influences on European surface temperature. Clim Dyn 17: 701715

Richman MB (1986) Rotation of principal components. J Climatol 6: $293-335$

Rodrigo FS, et al (2001) A reconstruction of the winter North Atlantic Oscillation Index back to 1501 using documentary data in Southern Spain. J Geophys Res 106: 14,805-14,818

Schmutz C, Wanner H (1998) Low frequency variability of atmospheric circulation over Europe between 1785 and 1994 Erdkunde 52: 81-94

Schmutz C, Luterbacher J, Gyalistras D, Xoplaki E, Wanner H (2000) Can we trust proxy-based NAO index reconstructions? Geophys Res Lett 27: 1135-1138

Schönwiese CD, Rapp J, Fuchs T, Denhard M (1993) KlimatrendAtlas Europa 1891-1990. Berichte des Zentrums für Umweltforschung der J.W.Goethe-University Frankfurt am Main, Germany, 20

Slonosky VC, Jones PD, Davies TD (2000) Variability of the surface atmospheric circulation over Europe, 1774-1995. Int J Climatol 20: 1875-1897

Slonosky VC, Jones PD, Davies TD (2001a) Atmospheric circulation and surface temperature in Europe from the 18th century to 1995. Int J Climatol 21: 63-75

Slonosky VC, Jones PD, Davies TD (2001b) Instrumental pressure observation from the 17th and 18th centuries: London and Paris. Int J Climatol 21: 285-298

Sturm K, Glaser R, Jacobeit J, Deutsch M, Brazdil R, Pfister C, Luterbacher J, Wanner H (2001) Hochwasser in Mitteleuropa seit 1500 und ihre Beziehung zur atmosphärischen Zirkulation. Petermanns Geogr Mitt 145(6): 14-23

Wanner H, et al (1994) Synoptic interpretation of monthly weather maps for the Late Maunder Minimum (1675-1704). Paleoclim Res 13: 401-424

Wanner H, et al (1995) Wintertime European circulation patterns during the Late Maunder Minimum cooling period (16751704). Theor Appl Climatol 51: 159-165

Wanner H, Gyalistras D, Luterbacher J, Rickli R, Salvisberg E, Schmutz C (2000) Klimawandel im Schweizer Alpenraum. Vdf Hochschulverlag AG, Zürich, pp 294 